\title{
Semantic Interference Effect in Picture-Word Naming Tasks between Youth and Elderly
}

\author{
Oh-Hyun Kim ${ }^{a}$, Soyoung Choi ${ }^{\mathrm{b}}$, Mina Hwang \\ ${ }^{a}$ Department of Speech-Language Pathology, Graduate School, Dankook University, Yongin, Korea \\ ${ }^{b}$ Graduate School of Special Education, Dankook University, Yongin, Korea \\ 'Department of Special Education, Dankook University, Yongin, Korea
}

\author{
Correspondence: Soyoung Choi, $\mathrm{PhD}$ \\ Graduate School of Special Education, Dankook \\ University, 152 Jukjeon-ro, Suji-gu, Yongin 16890, \\ Korea \\ Tel: +82-31-8005-3813 \\ Fax: +82-31-8021-7144 \\ E-mail: syc529@dankook.ac.kr
}

Received: July 2, 2016

Revised: August 14, 2016

Accepted: August 23, 2016

This article is based on a part of the first author's master's thesis from Dankook University.

\begin{abstract}
Objectives: The purpose of this study is to investigate whether elderly groups are able to do semantic processing during a picture-word interference task and whether their semantic processing is more affected by words in the same category or different categories. Methods: The participants in this study were 15 younger adults and 15 normal elderly. The tasks were composed of conditions where the target stimulation and distractive stimulation were in the same category or in different categories. The tasks were composed of a total of 30 questions. On the picture-word interference task, participants were supposed to name the picture. Results: The results of the study are summarized as follows. First, on the picture-word interference task, the accuracy of response of the elderly group was significantly lower than the younger group. Second, the reaction time of the elderly group was significantly slower, but both groups had a longer reaction time in the same category condition. Conclusion: The results indicated that the elderly group had more interference effects than the younger group. Although both groups resolved interference, the reaction time of the elderly group was slower. But in the same category condition, both groups had a longer reaction time than in different category conditions.
\end{abstract}

Keywords: Aging, Picture-word interference task, Semantic processing
2006년 보건복지부의 고령자 통계에 따르면 2007년을 기준으로 우리나라 전체 인구 중 65세 이상의 노인 인구 비율이 9.9\%로 노인 인구가 점차 증가함에 따라 고령화 사회(aging society)에 진입하고 있으며, 그 비율이 2018년에는 $14.3 \%, 2026$ 년에는 $20.8 \%$ 로 증가하 여 국민 5 명 중 1 명이 노인인 사회가 될 것으로 예상하고 있다(Kim \& Kim, 2009). 그러한 추세에 발맞추어 최근 노화(aging)에 따라 변화하는 노인들의 의사소통 능력에 대한 연구가 활발히 진행되면 서 고령화사회를 준비하는 토대가 되고 있다.

노인들은 신체적인 변화뿐만 아니라 고차적 인지기능의 변화를 겪게 되며, 이 같은 인지 기능의 문제는 기억력, 지남력, 주의, 집행 기능(executive function) 등 여러 요인들의 저하에서 비롯될 수 있 다(Park, 2015). 고차적 인지 기능 중 하나인 주의는 상황과 관계없 는 내·외적자극에 간섭 받지 않고 일정한 목표를 유지할 수 있는 능 력을 의미한다(Kim, 2012). Mirsky, Pascualvaca, Duncan과 French
(1999) 그리고 Parasuranam (1998)은 주의를 세 가지 개념으로 설 명하였다. 첫째, 시각, 청각, 촉각과 같은 특정 자극에 대한 분리된 반응에 주의해야 하는 초점 주의(focusing attention), 둘째, 연속적 이고 반복적인 활동을 수행하기 위해 지속적으로 반응을 유지해 야 하는 지속적 주의(sustaining attention), 셋째, 변별자극에 의존 하여 반응 억제와 활성을 돕는 인지적 세트를 유지해야 하는 선택 적 주의(selective attention)이다. 우리의 뇌는 수행에 필요한 정보 들만을 선택하여 처리하고 필요없는 정보들은 처리하지 않거나 무 시할 수 있지만, 동시적으로 들어온 정보들에 주의를 기울이지 못 하는 경우도 발생하게 된다. 노화로 인해 겪게되는 인지기능의 저 하는 동시적인 정보를 처리해야 하는 상황, 다시 말해 외부에서 주 어지는 그림, 글자, 소리, 촉감 등 다양한 형태의 자극을 받아들이 고 처리하는 과정에서 목표를 유지하는 능력과 밀접한 관계가 있 다. 이러한 일련의 과정은 일상생활에서 직면하는 문제들을 해결 
할 때뿐만 아니라 언어처리에도 필수적이다. 특히 목표유지 능력이 감소할 경우 과제에 집중하고 의미지식 내에서 관련된 구어정보를 인출(retrieval)하는 언어적 정보처리의 어려움을 보일 수 있으며, 순차적으로 입력되는 무수한 정보를 즉시적으로 취합해나가는 언 어처리 과정에서 노년층이 청년층에 비해 감퇴된 양상을 나타낸다 는 결과가 여러 연구들에서 보고된 바 있다(Kim, Hwang, Kim, \& Kim, 2013; Park, Lee, \& Lee, 2013). 또한 노인들은 기본적인 정보처 리 속도의 정확성이 떨어지고 주의력이 약해짐에 따라 청년층과 비 교하여 새로운 활동을 계획하거나 복잡한 결정을 내리는 과정 등 에서 어려움을 보이게 된다(Reese \& Rodeheaver, 1985). 뿐만 아니 라, 관련 없는 언어적 정보를 억제하지 못하고 지각적으로 현저하게 드러나는 언어적인 정보에만 의존해 문제를 해결하려는 경향을 보 일 수 있고, 나아가서는 어떤 판단을 하거나 문제를 해결하기 위해 주어진 정보를 통합하고 평가하는 과정에서 관련 없는 정보나 상 반된 정보를 충분히 억제하지 못하고 이에 간섭을 받아 문제해결의 정확성이 줄어드는 경험을 하기도 한다.

동시적으로 정보가 유입되는 언어처리 과정은 매우 신속하고 정 확하게 진행되지만 실제로 다양한 자극들을 처리하는 복잡한 과 정들이 관여하기 때문에 많은 노인들이 노화로 인한 의사소통의 어려움을 호소한다. 말소리 산출을 위해 화자는 의도에 적절한 개 념을 선택하여 활성화시키고 이를 심성어휘집(mental lexicon)에서 인출하여 적절한 음운 부호로 변환해야 한다. 많은 연구자들이 관 심을 갖고 연구한 어휘접근(lexical access) 과정은 단어의 의미를 처리하는 기초가 되며 자동적이고 내재적으로 일어나는 복잡한 과정의 산물이다(Ko, Choi, \& Hwang, 2010). 이 과정은 단어를 표 상하는 심성어휘집을 바탕으로 이루어지는데, 어휘의 의미와 철자, 발음, 다른 어휘와의 관계 등 단어와 관련된 여러 속성에 근거하여 최종적인 단어가 활성화된다(Carroll, 2007). 심성어휘집 내에는 재 인된 단어와 관련된 정보들이 의미 연결망(semantic network)을 구축하고 있으며, 이러한 연결은 촉진적이거나 억제적일 수 있고, 동시에 활성화된 단어들은 서로 경쟁하며 처리된다고 알려져 있다 (Whitney, 2003). 단어인출 과정에서 진행되는 어휘접근 과정의 특 성을 분석하기 위해 대표적으로 사용되어온 과제 중 하나로서 정 보들 간의 경쟁을 연구하는 간섭과제를 들 수 있다(MacLeod \& MacDonald, 2000). 간섭과제란 표적자극(target stimuli)에 비해 방해자극(distractor stimuli)이 깊이 처리되어 표적반응에 대한 간 섭을 일으키게 되는 과제로, 과제 수행 시 나타나는 간섭의 양상을 관찰함으로써 지각 정보처리의 구조와 기능에 관한 다양한 가설 을 검증할 수 있다. 방해자극은 선택적 주의 여부에 따라 표적자극 의 처리에 달리 영향을 미칠 수 있는데, 강한 방해자극이 나타난상
황에서도 표적자극에 선택적으로 주의가 집중되어 있다면 간섭이 적게 발생할 것이고, 이와 반대로 약한 방해자극이라 하더라도 선 택적 주의를 유지하기 어려워지면 많은 간섭효과가 나타날 수 있다 (Shon \& Yang, 2006). 초기에 고안된 스트룹 과제는 불필요한 정보 의 간섭을 억제하고 과제의 목표를 성공적으로 활성화하는 수행을 요구하였다(Stroop, 1935). 예를 들면, 대상자에게 색깔 명칭의 단 어를 그 의미와 일치하지 않는 색으로 제시하고 단어 읽기가 아닌 색상 말하기를 요구하였을 때(예: ‘초록'이라는 단어를 빨강색으로 제시하면 ‘빨강'이라고 답해야 함) 색 판단에 대한 색 단어의 간섭 량을 측정하여 간섭효과 양상을 유추하는 것이었다(Dyer \& Severance, 1973; Goolkasian, 1981). 즉, 주어진 단어를 읽는 자동적인 반응 과정에서 우세한 반응인 단어 읽기를 억제하고 상대적으로 덜 우세한 색 이름 말하기를 수행할 때 오류가 증가하고 반응시간 이 느려지게 된다.

일부 연구자들은 이를 토대로 변형된 그림-단어 간섭과제(picture-word interference task)를 사용하여 주의력과 의미처리 과정의 관계를 규명하고자 하였다(Damian \& Martin, 1999; Koo \& Nam, 2007). 그림-단어 간섭과제는 표적자극(그림)과 시간적으로 근접하 게 제시되는 방해자극(단어)은 무시하고, 본래의 목표를 유지하며 방해자극들을 억제하여 표적자극의 이름을 빠르고 정확하게 명명 해야 하는 과제이다(Koo, 2014). 이를 통해 의미처리 과정에 관해 알아보고자 한 다수의 연구들은 주어지는 표적자극과 방해자극 간의 범주 일치-불일치 여부에 따라 반응정확도나 반응시간을 측 정하였고, 반응의 목표인 표적자극의 목록과 간섭을 유발하는 방 해자극의 목록이 동일한 범주에서 주어질 경우 단어를 판단하거나 명명하는 수행 시 간섭 강도가 크다는 결과를 보고하였다(Hartendorp, Van der Stigchel, \& Postma, 2013; Lee, Min, \& Yi, 2011). 이러 한 연구 결과는 복합적인 자극을 처리할 때 세분화된 자극의 범주 와 제한된 주의 자원 용량이 영향을 주었기 때문으로 해석되었다 (Jenkins, Lavie, \& Driver, 2003; Rhim \& Yi, 2010). 노화로 인한 인 지적 쇠퇴는 방해요인들로부터 목표를 유지하는 과정에 어려움을 유발하고, 표적자극(그림)과 방해자극(글자)이 서로 동일 범주로 주어지는 상황에서 더 큰 강도의 간섭을 발생시킬 수 있다(Braver \&West, 2008; DeJong, 2001; Rush, Barch, \& Braver, 2006). 즉, 노인 들의 경우 동시에 활성화된 여러 단어들 중 불필요한 의미정보를 억제하는 능력이 부족하거나 약화되어 있기 때문에 단어를 재인하 여 의미 연결망에 접근하고 이를 통해 관련된 의미정보를 활성화시 켜 반응을 산출하는 처리 과정에서 청년에 비해 방해자극들로부 터 더 많은 간섭을 받는다는 것이다(Hasher \& Zacks, 1988; Hasher, Zacks, \& May, 1999). 
그러나 최근까지도 국내에서 진행된 연구는 정상적인 언어 기능 을 가진 일반 대학생들을 대상으로 진행되었을 뿐(Koo \& Nam, $2007 ; \mathrm{Koo}, 2014)$ 노화에 따른 어휘 접근 과정의 변화를 경험적으 로 관찰한 사례가 드물고, 특히 표적자극 목록과 방해자극 목록의 범주 일치 여부를 언어 과제를 통해 살펴본 연구는 찾아보기 어렵 다. 이러한 맥락에서 본 연구는 그림-단어 간섭과제 수행에서 나타 나는 간섭효과의 양상을 비교함으로써 청년층과 노년층의 어휘 접 근 및 의미처리 과정에 차이가 있는지 살펴보고자 하였다. 이를 위 하여 목표유지가 요구되는 시각적 제시형식(visual modality)의 실 시간 판단과제인 그림-단어 간섭과제를 사용하였으며, 방해자극을 무시하고 표적자극에 주의를 기울여 정답에 해당하는 단어를 정 확하고 빠르게 명명하도록 하였다. 더불어 동일 범주의 방해자극 이 제시되는 조건과 그렇지 않은 조건에서 수행의 정확도와 그에 따른 반응시간을 함께 측정하였다.

\section{연구 방법}

\section{연구 대상}

본 연구는 청년층과 노년층의 의미처리 능력을 비교하기 위해 서 울 및 경기 지역에 거주하는 20 대 성인 15 명과 65 세 이상 노인 15 명 으로 집단을 구성하였고, 두 집단의 참가자는 모두 한국어가 모국 어이며 문맹이 아닌 이들이었다. 본 연구의 노인대상자는 (1) KMMSE (Korean Mini-Mental State Examination; Kang, Na, \& $\mathrm{Hahn}, 1997)$ 에서 점수가 해당 연령 및 교육년수 규준에서 $16 \% \mathrm{ile}$ 이상에 속하며(Kang, 2006), (2) 대상자 본인이나 보호자의 보고에 의해 인지기능에 영향을 미칠 수 있는 신경학적, 정신적 질병이 없 고, (3) 과제 수행 및 지시 따르기에 필요한 정상적인 시각 및 청각 능력을 가지고 있는 이들로 선정하였다. 두 집단의 교육 수준은 통 계적으로 유의한 차이가 나지 않도록 통제하였다 $(t=1.551, p>.05)$. 집단별 대상자 정보는 Table 1과 같다.

\section{연구 도구}

본 연구의 그림-단어 간섭과제에 사용하기 위한 단어 목록을 구

Table 1. Descriptive information of participants

\begin{tabular}{lcc}
\hline & Youth $(\mathrm{N}=15)$ & Elderly $(\mathrm{N}=15)$ \\
\hline Age (yr) & $21.66(1.58)$ & $73.00(5.35)$ \\
Education (yr) & $13.20(1.42)$ & $14.26(2.25)$ \\
K-MMSE & - & $28.60(1.45)$ \\
\hline
\end{tabular}

Values are presented as mean (SD).

K-MMSE = Korean version of Mini-Mental Status Examination (Kang, Na, \& Hahn, 1997).
성하기 위해 Kim (2005)과 Finkbeiner와 Caramazza (2006)의 연 구를 참고로 하여 과일, 동물, 의복으로 범주유형을 선정하고 범주 단어를 구성하였다. 자극으로 사용한 단어는 (1) 고유 명사 및 추상 명사를 제외한 구체 명사만을 선택하였으며, (2) Kim (2005)의 연 구를 참고하여 빈도수가 20-400에 속하는 2음절 단어를 선정하였 다. 최종적으로 세 개의 범주당 5 개씩의 단어를 포함하여 그림자극 (표적자극)과 글자자극(방해자극)의 범주가 일치하는 조건 15 개 문항과 범주가 불일치하는 조건 15 개 문항으로 총 30 문항을 구성 하였으며, 대상자가 반복적으로 목표자극에만 집중할 가능성을 고려하여 목표자극과 방해자극이 동일한 9 개의 Filler 문항을 추가 로 제작하였다. 즉, 범주 일치 조건은 과일 범주의 사과 그림이 시각 적으로 제시될 때 동일한 범주의 단어 “딸기”가 겹쳐서 제시되고, 범주 불일치 조건은 과일 범주의 포도 그림이 제시될 때 다른 범주 인 동물 단어 “토끼”가 겹쳐서 제시되었다. 자극 단어 목록은 Appendix 1 에 제시하였다. 일반 대학생 10 명에게 진행된 사전 연구를 통해 제시된 그림에 대하여 목표로 하는 이름대기 반응이 산출되 는지 검토하였고, 애매한 자극을 교체하여(예: 키위 $\rightarrow$ 참외) 적절성 에 대한 타당도를 확인하였다.

실험자극 화면은 Damian과 Bowers (2003)의 연구를 수정·보완 하여 그림자극(표적자극) 내에 글자자극(방해자극)을 겹쳐서 제시 하였다. Yang, Lim과 Bae (2015)의 연구를 참고하여 청년 집단과 노 인 집단 각각 5 명씩 10 명에게 예비실험을 한 결과, 흰 바탕에 검은 선화보다 검은 바탕에 흰 선화에서 더 확실한 간섭효과가 나타남 에 따라 본 실험의 자극은 검은 바탕에 흰색 선화 및 흰색 글씨로 제시하였다. 그림자극(표적자극)의 크기는 가로 $\times$ 세로 300 픽셀이 었으며, 글자자극(방해자극)은 맑은 고딕체로 크기는 $28 \mathrm{pt}$ (8-10 $\mathrm{mm}$ )였다. 실험자극 제시의 예는 Appendix 2와 같다.

\section{연구 절차}

과제는 E-Prime 프로그램을 이용하여 제작하였으며, 소음이 차 단된 공간에서 개별적으로 실시하였다. Samsung NT-R410 컴퓨터 의 $14 \mathrm{inch}$ 화면 중앙에 자극을 제시하였고, 참가자와 모니터 사이의 거리는 일정하게 유지하였다. 구체적인 절차는 다음과 같다(Figure 1). $500 \mathrm{~ms}$ 동안 화면 중앙에 응시점(+)이 제시되었다가 사라지면 실험 자극이 나타났으며, 시행과 시행 사이에는 빈 화면이 $500 \mathrm{~ms}$ 동안 제시되었다. 참가자의 구두 반응이 완료되면 연구자가 버튼을 조작하여 다음 시행으로 진행하였고, $5,000 \mathrm{~ms}$ 동안 음성 반응이 없을 경우 자동으로 다음 시행으로 넘어가도록 하였다. 참가자에 게는 글자자극(방해자극)은 무시하고 그림자극(표적자극)에 해당 하는 단어를 최대한 빠르고 정확하게 산출하도록 지시가 주어졌 


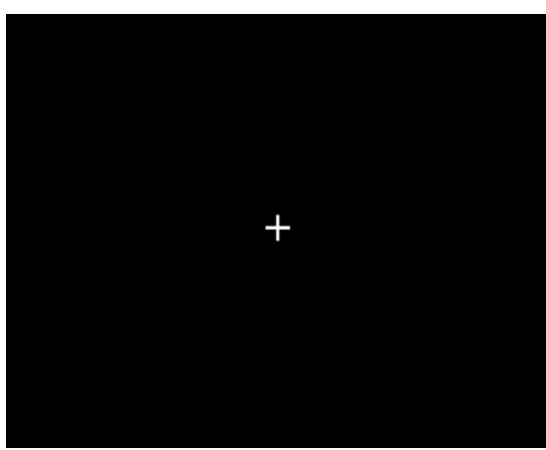

$500 \mathrm{~ms}$

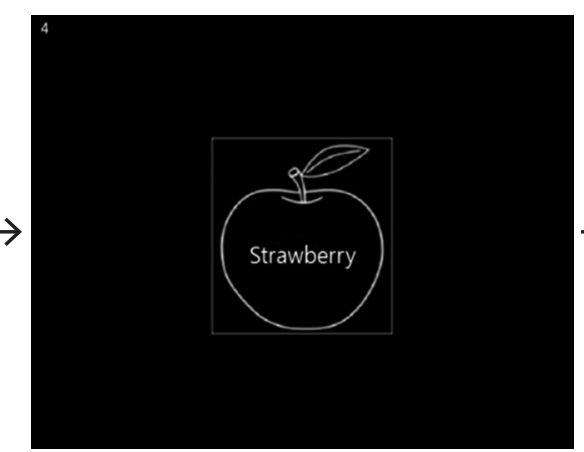

$5,000 \mathrm{~ms}$

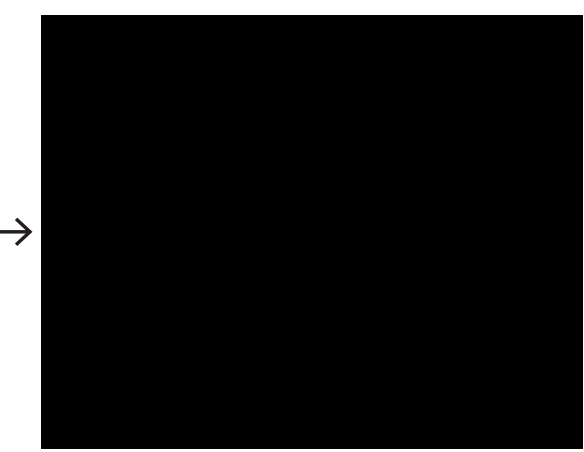

$500 \mathrm{~ms}$

Figure 1. Procedures of the task.

다. 모든 자극은 1 회만 제시하였고, 참가자의 모든 반응은 response box를 통해 컴퓨터에 녹음되어 파일로 저장되었다.

4 회의 연습시행 이후 본 시행을 수행하였고, 참가자가 과제 방식 을 이해하지 못했을 경우 연습시행을 반복 실시한 후 본 시행을 진 행하였다. 모든 문항은 무선배열 하였고, 전체 과제를 수행하는 데 약 15 분이 소요되었다.

\section{자료 분석}

두 집단의 범주 일치 여부에 따른 그림-단어 간섭과제의 이름대 기 수행 결과에 대한 정반응 점수와 반응시간을 분석하였다. 참가 자의 수행 결과는 정반응 1 점, 오반응 0점으로 기록하였고, 범주 일 치 조건과 범주 불일치 조건에 대하여 각 15 점을 총점으로 하였다. 반응시간은 저장된 음성 파일 각각에서 실험자극이 제시된 시점부 터 참가자가 구두로 응답을 시작하기까지의 음성 개시 시간(voice onset time)으로 측정하였다. 참가자가 정반응 한 경우의 반응시간 만 분석에 포함하였으며, 평균 반응시간에서 $2 \mathrm{SD}$ 이상 벗어나는 경우 분석에서 제외하도록 하였으나 이에 해당하는 극단값은 관찰 되지 않았다.

수집된 자료는 SPSS 통계 프로그램으로 분석하였다. 연령에 따 른 두 집단 간 범주 일치 여부에 따른 이름대기 수행에 유의한차이 가 있는지 알아보기 위해, 집단(2)과 범주 일치 여부(2)를 요인으로 하는 반복측정 이원분산분석(repeated measure two-way ANO$\mathrm{VA})$ 을 실시하였다.

Table 2. Number of correct response according to the groups and conditions

\begin{tabular}{lcc}
\hline & Youth $(\mathrm{N}=15)$ & Elderly $(\mathrm{N}=15)$ \\
\hline Same category condition & $15.00(0)$ & $14.33(.97)$ \\
Different category condition & $15.00(0)$ & $14.93(.25)$ \\
\hline
\end{tabular}

Values are presented as mean (SD).

\section{연구 결과}

청년 집단과 노인 집단이 그림-단어 간섭과제를 수행한 결과에 대한 정반응 수의 평균과 표준편차는 Table 2 와 같다. 표적자극과 방해자극의 범주 일치-불일치 여부에 따라 두 집단 간 그림-단어간 섭과제 의미처리 능력의 반응정확도에 차이가 있는지 알아보기 위 해 이원분산분석을 실시한 결과, 집단의 주효과 $\left(F_{(1,28)}=7.563, p<.05\right)$ 와 범주 일치 여부의 주효과 $\left(F_{(1,28)}=5.559, p<.05\right)$ 가 통계적으로 유 의미하였다. 다시 말해, 노인 집단의 반응 정확도가 청년 집단에 비 해 낮았으며, 범주 일치 조건에서 범주 불일치 조건보다 낮은 반응 정확도가 관찰되었다. 집단과 범주 일치 여부 요인의 상호작용 효과 도 유의미한 것으로 나타났는데 $\left(F_{(1,28)}=5.559, p<.05\right)$, 이는 청년 집단의 경우는 두 조건 모두에서 15 점의 정확도를 보여 조건 간의 차이가 나타나지 않았으나 노인 집단의 경우 범주 일치 조건에서 다소 저조한 수행을 보였기 때문으로 해석할 수 있었다.

화면에 목표자극이 제시된 시점부터 참가자가 반응을 산출하는 음성이 개시된 시간까지로 측정된 반응시간에 대한 두 집단의 기 술통계 결과는 Table 3과 같다. 두 집단 간의 범주 일치 여부에 따른 그림-단어 간섭과제 의미처리 능력의 반응시간 차이를 알아보기 위해 이원분산분석을 실시한 결과, 집단에서 주효과가 유의미하였 고 $\left(F_{(1,28)}=50.198, p<.001\right)$, 범주 일치 여부에서의 주효과 또한 유 의미하였다 $\left(F_{(1,28)}=17.836, p<.001\right)$. 즉, 청년 집단에 비해 노인 집 단의 반응시간이 유의미하게 느렸으며, 범주 불일치 조건보다 범주

Table 3. Reaction time according to the groups and conditions (unit: ms)

\begin{tabular}{lcc}
\hline & Youth (N=15) & Elderly (N=15) \\
\hline Same category condition & $947.92(143.87)$ & $1,550.89(261.56)$ \\
Different category condition & $915.52(150.32)$ & $1,452.30(277.38)$ \\
\hline
\end{tabular}

Values are presented as mean (SD). 


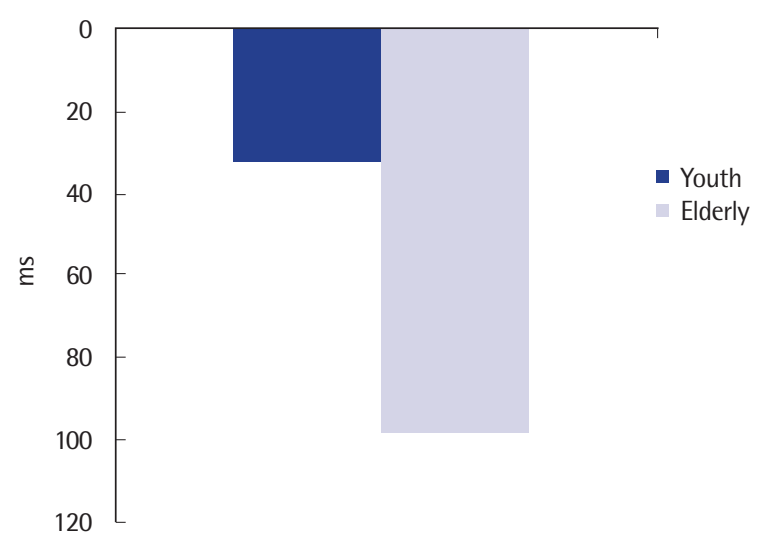

Figure 2. Different interference effects in youth and elderly.

일치 조건에서 반응 개시가 지연되는 양상이 관찰되었다.

또한 집단과 범주 일치 여부의 상호작용 효과도 유의미하였는데 $\left(F_{(1,28)}=4.433, p<.05\right)$, 그 차이는 간섭효과의 크기에 기인한 것으 로 보인다. 범주 불일치 조건보다 범주 일치 조건에서 길어진 반응 시간이 간섭효과가 반영된 결과라고 보았을 때, Figure 2에 제시한 바와 같이 청년 집단은 조건 간의 차이가 평균 $32.40 \mathrm{~ms}$ 였던 것에 반해 노인 집단은 평균 $98.59 \mathrm{~ms}$ 의 차이를 보임에 따라 범주 일치 여부에 따른 영향을 더 크게 받는 것으로 나타났다.

\section{논의 및 결론}

본 연구는 20 대 청년 집단과 65 세 이상 노인 집단의 범주 일치-불 일치 여부에 따른 그림-단어 간섭과제의 의미처리 능력에 차이가 있는지에 대해 살펴보았다. 이름대기 반응정확도에서 두 집단 간의 차이가 통계적으로 유의미하였고, 노인 집단의 반응정확도가 다소 낮게 나타났지만 두 집단에서 모두 매우 높은 반응정확도가 관찰 되었으며 특히 청년 집단의 평균은 천정 효과(ceiling effect)를 보였 다. 범주 일치 여부에 따른 차이 역시 노인 집단에서만 범주 일치 조 건의 수행이 다소 낮게 나타났을 뿐이어서 그림-단어 간섭과제의 반응정확도만으로는 노인 집단이 방해자극을 억제하는데 실패한 것으로 해석하기에 제한이 있었다. 그러나 집단 및 범주 일치 여부 조건 간의 차이는 이름대기 반응시간에서 보다 명확히 드러났다. 집단 간의 차이와 범주 일치 여부에 따른 차이가 모두 통계적으로 유의미하였는데, 이를 통해 노인 집단도 간섭효과를 극복하고 이 름대기 수행에 성공할 수 있었으나 청년 집단에 비해 방해자극을 억제하고 표적자극을 명명하는 데 더 오랜 시간이 소요됨을 알 수 있었다. 특히 청년 집단은 조건 간의 차이가 미미하였으나 노인 집 단의 경우 범주 일치 조건에서 반응시간이 더 길게 나타난 결과는,
표적자극과 방해자극이 동일한 범주에서 제시되었을 때 의미적 근 접성에서 유발되는 간섭효과가 커지며 억제의 효율성이 저하된 노 인들은 언어 처리 과정에 더 많은 방해를 받게 되고 그 결과 수행 시 간이 지연되는 양상을 보이게 됨을 시사하였다.

이 같은 결과는 청년 집단을 대상으로 표적자극(예: 바지)과 의미 적으로 연관이 있는 방해자극(예: 치마)은 의미적으로 관련이 없는 방해자극(예: 화산)에 비해 표적자극에 대한 정보 처리를 크게 간 섭하기 때문에 명명시간이 지연되는 의미간섭효과를 일으킨다고 보고한 선행 연구들과 일치하였고(Ahn, Lee, \& Yi, 2015; Hartendorp et al., 2013; Koo \& Nam, 2007; Young, Ellis, Flude, McWeeny, \& Hay, 1986), 노화가 진행됨에 따라 인지 및 언어 기능이 저하된 노 인에게도 유사한 의미 처리 과정이 존재하지만 목표를 유지하여 방 해자극에 대한 간섭을 억제하고 의미를 처리해야 하는 과제에서 청년보다 더욱 큰 간섭의 영향을 받았을 것임을 확인해주었다.

Warren과 Morton (1982)에 따르면 그림자극과 단어자극이 동 시에 입력되었을 때, 초기에는 그림과 단어의 독립적인 시각적 분석 이 이루어지고, 자극으로부터 특징적인 정보를 추출하여 의미를 처리하게 된다. 한편, Caramazza (1997)와 Cheng, Schafer와 Akyürek (2010)은 이름대기 과정이 사물을 인지하고 자극을 해독하는 개념 활성화(concept activation), 사물에 상응하는 소리패턴을 선 택하는 어휘화(lexicalization), 어휘를 말소리로 변화시키는 조음 (articulation)과 같은 순차적인 단계를 거치게 된다고 하였다. 이를 통합한 Koo (2014)의 가설에 따르면 그림자극은 개념화, 어휘화, 조 음단계를 순차적으로 거치는 반면, 글자자극은 이미 음운표상을 거쳐 바로 조음단계로 처리될 수 있다. 즉, 여러 과정을 거쳐 명명해 야 하는 그림자극에 비해 상대적으로 처리과정이 덜 복잡한 글자 자극이 더 빠르게 처리될 수 있다는 것이다. 위와 같은 선행연구들 에 비추어 본 연구의 결과를 살펴보면 첫째, 그림자극과 글자자극 은 각각을 대표하는 물체로 표상하게 되고 각각의 표상은 인지시스 템에서 처리되는데(Warren \& Morton, 1982), 노인 집단은 점차 노 화함에 따라 목표유지 감소는 물론, 언어 처리 및 판단과 같은 고차 적 인지기능을 처리하는 능력이 감소하기 때문에 충분히 간섭을 억 제하지 못하거나 적절한 수준의 억제를 수행하는 효율성이 떨어져 더 많은 노력과 시간이 필요했을 수 있다. 둘째, 시각적인 자극 표상 을 통해 그 의미를 인출해야 하는 그림자극은 언어적 산출을 위한 인지적 과정을 한 번 더 거쳐야 하지만, 숙련된 독자의 글자자극 재 인은 자동적으로 일어나기 때문에 인지적 과정을 거치지 않고 자 극을 명명하기 위한 프로그램 단계인 산출 어휘집 과정으로 직접 정보가 보내질 수 있다(Rayner \& Springer, 1986). 노인들은 인지시 스템을 거치지 않고 바로 산출 어휘집으로 가는 글자자극에 비해 
인지적 처리를 요하는 그림자극을 명명하는 데 더 많은 시간이 요 구될 뿐 아니라, 그림자극보다상대적으로 먼저 처리된 글자자극을 억제하는 것에 실패하여 제시된 글자를 명명하는 오류를 보였을 수 있다. 다시 말해, 본 연구의 과제에서 서로 같은 범주에 속하는 '사과' 그림(표적자극)과 ‘딸기' 글자(방해자극)가 동시에 제시되었 을 때 추가적인 인지 처리 단계가 필요한 그림자극보다 상대적으로 덜 복잡한 과정을 거치는 글자자극이 더 빠르게 처리되었을 수 있 다. 그 결과 참가자는 상대적으로 빠르게 처리된 방해자극의 간섭 을 받아 ‘딸기’를 명명하여 오반응 하거나 방해자극을 억제하기 위 해 더 많은 시간과 노력이 소요되어 정반응이 지연되는 양상을 보 이게 된 것으로 해석된다.

현재까지 많은 말소리 산출 모형들은 의미간섭효과가 비언어적 메시지를 구성하는 수준의 개념 선택 단계가 아닌 선택된 개념에 적합한 어휘를 심성어휘집 내에서 인출하는 단계에 발생한다고 가 정하고 있다. 이러한 관점으로 말소리 산출 과정에서 발생하는 의 미간섭효과를 설명하는 하나의 축이 활성화-경쟁 가설(competition-by-activation hypothesis)이다. 이 가설에 따르면 이름대기 수 행을 위해 심성 어휘집에 접근하여 목표 단어를 인출하는 과정에 서 표적자극과 방해자극에 의해 각각 활성화된 여러 어휘 항목들 이 동시적으로 경쟁하면서 간섭이 발생한다. 특히 표적자극과 의미 적으로 유사한 방해자극의 경우 관련이 없는 방해자극에 비해 더 높은 활성화 수준을 유지하기 때문에 의미간섭효과가 상대적으로 크게 나타나게 된다(Roelofs, 1992). 한편, 보다 최근들어 제안된 Finkbeiner와 Caramazza (2006)의 반응선택 가설(response selection hypothesis)은 의미간섭효과가 어휘 접근 이후의 처리과정 (post-lexical level processing)에서 발생한다고 보았다. 그림-단어 간섭과제에서 방해자극(글자)의 음운 표상은 표적자극(그림)보다 빨리 구성되어 반응 버퍼에 입력되며, 표적자극의 음운 표상이 추 후 입력되면 반응 버퍼는 두 개의 음운 표상을 가지게 된다. 반응 버 퍼는 음운 표상을 하나씩 인출할 수 있기 때문에 방해자극의 음운 표상은 억제되어야 하며, 두 자극이 의미적으로 관련되어 있는 경 우 억제 처리에 더 긴 시간이 소요된다는 것이다. 전자에 따르면 본 연구의 동일 범주 조건에서 '사과' 그림(표적자극)과 '딸기' 글자(방 해자극)가 주어졌을 때 의미적으로 유사한 두 항목이 동시에 활성 화되어 유지됨으로 인해 경쟁과 간섭이 발생하게 되고 결과적으로 이름대기 수행에 어려움을 유발하였을 것으로 추정된다. 후자에 의하면 방해자극인 '딸기'가 먼저 반응 버퍼에 입력되어 있는 상태 에서 표적자극인 '사과'가 입력되고 두 개의 음운 표상 중 방해자극 인 '딸기'는 억제하고 '사과'를 인출해야 할 때, 두 개의 표상이 서로 같은 범주인 까닭에 억제 처리에 어려움을 겪게 되어 다른 범주의
방해자극(예: 고래)이 제시된 조건에 비해 반응시간이 증가하는 결 과가 관찰된 것으로 해석할 수 있을 것이다. 두 가설을 통해 노인들 은 높은 활성화 수준을 가졌거나 시간적으로 먼저 입력된 방해자 극에 대한 억제 기제가 청년층에 비해 약화되어 있다는 점을 추정 해볼 수 있으나 본 연구 결과만으로 의미간섭효과를 보다 적절히 설명하는 가설을 밝히기에는 한계가 있어 후속 연구가 요구된다.

본 연구는 노인 집단이 그림-단어 간섭과제를 수행할 때 방해자 극의 억제에 완전히 실패하는 것은 아니지만 표적자극과 관련이 있 는 방해자극이 주어질 경우 목표 유지가 상대적으로 어렵게 되고, 이처럼 간섭효과가 증가한 상황에서는 결과적으로 의미처리에 오 류를 보이거나 처리 시간이 지연되는 양상을 보이게 됨을 경험적으 로 확인하였다. 즉, 노인들은 복잡성과 처리 부담이 증가한 언어 과 제에서 억제가 요구되는 간섭 자극이 함께 주어졌을 때, 처리에 더 긴 시간이 소요될 뿐 아니라 간섭을 적절히 억제하지 못했을 경우 부적절한 언어 반응을 산출할 수도 있다. 그러나 추후 연구를 통해 본 연구 결과에서 나타난 것과 같은 노인 집단의 수행 특성이 어떤 인지적·언어적 요인(예: 작업기억, 실행기능 등)에서 비롯되는 것인 지에 대한 확인이 필요하며, 나아가 급격하고 심각한 병리적 기능 저하를 보이는 집단에 대한 탐색도 이어져야 할 것이다.

언어능력과 밀접하게 연관된 인지기능이 노년기로 접어들면서 감퇴되어가고 이로 인해 의사소통 능력의 저하가 촉발되는 것은 불 가피하다. 특히 일상적인 의사소통 상황에서는 언어 정보들이 동시 적으로 제시되는 경우가 많으며, 이때에는 억제해야 할 정보와 의 미 있게 처리해야 할 정보를 스스로 구분할 수 있어야 한다. 뿐만 아 니라 본 연구의 실험 조건에서와 같이 외부적인 간섭 요소가 없을 지라도 복잡한 언어 처리 과정에서는 내재되어 있는 정보들의 경쟁 에서 처리와 억제를 선택하고 판단하는 조절 능력이 요구된다. 때 문에 노인들이 실제 언어 사용 환경에서 겪는 어려움은 본 연구 결 과에서 나타난 반응시간의 증가보다 더 심각할 수 있다. 그러므로 병리적 노화를 겪는 이들뿐만 아니라 정상적인 노화과정으로 인해 의사소통의 어려움을 겪는 이들의 문제를 해결하는 것도 그들의 삶의 질을 향상시키는데 기여할 수 있을 것이다.

\section{REFERENCES}

Ahn, S. H., Lee, Y. J., \& Yi, D. J. (2015). Redundant interference: evidence for the coactivation model in a word-picture Stroop task. Korean Journal of Cognitive and Biological Psychology, 27, 313-319.

Braver, T. S., \& West, R. (2008). Working memory, executive control, and aging. The Handbook of Aging and Cognition, 3, 311-372. 
Caramazza, A. (1997). How many levels of processing are there in lexical access? Cognitive Neuropsychology, 14, 177-208.

Carroll, D. W. (2007). Psychology of language (5th ed., K. O. Lee \& H. S. Park, Trans.). Seoul: Pakhaksa.

Cheng, X., Schafer, G., \& Akyürek, E. G. (2010). Name agreement in picture naming: an ERP study. International Journal of Psychophysiology, 76, 130141.

Damian, M. F., \& Bowers, J. S. (2003). Locus of semantic interference in picture-word interference tasks. Psychonomic Bulletin \& Review, 10, 111-117.

Damian, M. F., \& Martin, R. C. (1999). Semantic and phonological codes interact in single word production. Journal of Experimental Psychology: Learning, Memory, and Cognition, 25, 345-361.

De Jong, R. (2001). Adult age differences in goal activation and goal maintenance. European Journal of Cognitive Psychology, 13, 71-89.

Dyer, F. N., \& Severance, L. J. (1973). Stroop interference with successive presentations of separate incongruent words and colors. Journal of Experimental Psychology, 98, 438-439.

Finkbeiner, M., \& Caramazza, A. (2006). Now you see it, now you don't: on turning semantic interference into facilitation in a Stroop-like task. Cortex, 42, 790-796.

Goolkasian, P. (1981). Retinal location and its effect on the processing of target and distractor information. Journal of Experimental Psychology: Human Perception and Performance, 7, 1247-1257.

Hartendorp, M. O., Van der Stigchel, S., \& Postma, A. (2013). To what extent do we process the nondominant object in a morphed figure? Evidence from a picture-word interference task. Journal of Cognitive Psychology, 25, 843-860.

Hasher, L., \& Zacks, R. T. (1988). Working memory, comprehension, and aging: a review and a new view. Psychology of Learning and Motivation, 22, 193-225.

Hasher, L., Zacks, R. T., \& May, C. P. (1999). Inhibitory control, circadian arousal, and age. In D. Gopher \& A. Koriat (Eds.), Attention and performance XVII: cognitive regulation of performance: interaction of theory and application (pp. 653-675). Cambridge, MA: The MIT Press.

Jenkins, R., Lavie, N., \& Driver, J. (2003). Ignoring famous faces: categoryspecific dilution of distractor interference. Perception \& Psychophysics, 65, 298-309.

Kang, Y. (2006). A normative study of the Korean-Mini Mental State Examination (K-MMSE) in the elderly. Korean Journal of Psychology: General, 25, 1-12.
Kang, Y., Na, D. L., \& Hahn, S. (1997). A validity study on the Korean MiniMental State Examination (K-MMSE) in dementia patients. Journal of the Korean Neurological Association, 15, 300-308.

Kim, H. (2012). Neurogenic speech-language disorders. Seoul: Sigmapress.

Kim, H. S. (2005). Research on the frequency of used modern Korean language 2. Seoul: National Institute of Korean Language.

Kim, J. W., \& Kim, H. (2009). Communicative ability in normal aging: a review. Korean Journal of Communication Disorders, 14, 495-513.

Kim, J. W., Hwang, J. H., Kim, S. R., \& Kim, H. (2013). Differences in attention and naming ability with age in the elderly. Journal of Speech \& Hearing Disorders, 22, 25-44.

Ko, S., Choi, K. S., \& Hwang, M. (2010). Comprehension of ambiguous words in children with poor reading comprehension. Korean Journal of Communication Disorders, 15, 348-356.

Koo, M. M. (2014). Semantic interference effect: evidence from a loanword study. Journal of Linguistic Science, 68, 1-18.

Koo, M. M., \& Nam, K. C. (2007). The locus of the word frequency effect in speech production: evidence from the picture-word interference task. Malsori, 62, 51-68.

Lee, J. Y., Min, S. J., \& Yi, D. J. (2011). Dilution and redundancy effects on Stroop interference. Korean Journal of Cognitive Science, 22, 469-494.

MacLeod, C. M., \& MacDonald, P. A. (2000). Interdimensional interference in the Stroop effect: uncovering the cognitive and neural anatomy of attention. Trends in Cognitive Sciences, 4, 383-391.

Mirsky, A. F., Pascualvaca, D. M., Duncan, C. C., \& French, L. M. (1999). A model of attention and its relation to ADHD. Mental Retardation and Developmental Disabilities Research Reviews, 5, 169-176.

Parasuranam, R. (1998). The attentive brain: issues and prospects. In R. Parasuraman (Ed.), The attentive brain (pp. 3-15). Cambridge, MA: MIT Press.

Park, J. Y., Lee, K. E., \& Lee, H. W. (2013). The effects of aging on retrieval of phonological knowledge in Korean: the tip-of-the-tongue phenomenon in young and older adults. Korean Journal of Cognitive Science, 24, 111-132.

Park, S. (2015). Cognitive aging and language: a psycholinguistic approach. Studies in Modern Grammar, 83, 25-39.

Rayner, K., \& Springer, C. J. (1986). Graphemic and semantic similarity effects in the picture-word interference task. British Journal of Psychology, $77,207-222$.

Reese, H. W., \& Rodeheaver, D. (1985). Problem solving and complex decision making. In J. E. Birren (Ed.), Handbook of the psychology of aging (2nd ed., pp. 474-499). San Diego, CA: Academic Press. 
Rhim, J. H., \& Yi, D. J. (2010). The effects of perceptual load and categoryspecific dilution on visual search. Korean Journal of Cognitive Science, 21 , 177-197.

Roelofs, A. (1992). A spreading-activation theory of lemma retrieval in speaking. Cognition, 42, 107-142.

Rush, B. K., Barch, D. M., \& Braver, T. S. (2006). Accounting for cognitive aging: context processing, inhibition or processing speed? Aging, Neuropsychology, and Cognition, 13, 588-610.

Shon, Y. S., \& Yang, H. J. (2006). Does selective attention differentially modulate within-versus between-hemisphere interference? Korean Journal of Experimental Psychology, 18, 263-280.

Stroop, J. R. (1935). Studies of interference in serial verbal reactions. Journal of Experimental Psychology, 18, 643-662.

Warren, C., \& Morton, J. (1982). The effects of priming on picture recognition. British Journal of Psychology, 73, 117-129.

Whitney, P. (2003). The psychology of language (S. B. Lee \& K. S. Han, Trans.). Seoul: Sigmapress.

Yang, Y., Yim, D., \& Bae, K. (2015). Predictors of word learning in children with specific language impairment. Communication Sciences \& Disorders, $20,1-12$.

Young, A. W., Ellis, A. W., Flude, B. M., McWeeny, K. H., \& Hay, D. C. (1986). Face-name interference. Journal of Experimental Psychology: Human Perception and Performance, 12, 466-475. 
Appendix 1. 과제 단어 목록

\begin{tabular}{lll}
\hline 과일 & 동물 & 의복 \\
\hline 사과 & 돼지 & 바지 \\
딸기 & 토끼 & 치마 \\
포도 & 사자 & 모자 \\
수박 & 고래 & 장갑 \\
참외 & 오리 & 양말 \\
\hline
\end{tabular}

Appendix 2. 조건별 과제 제시의 예

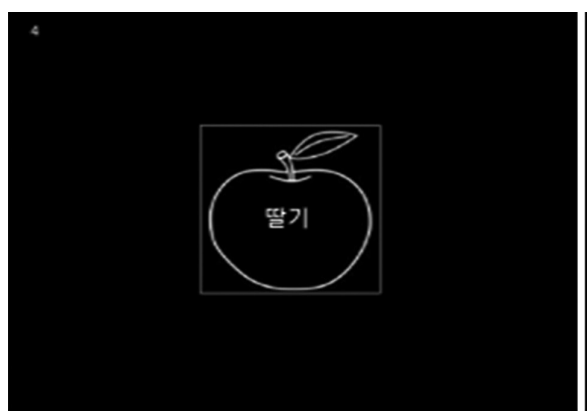

범주 일치 조건

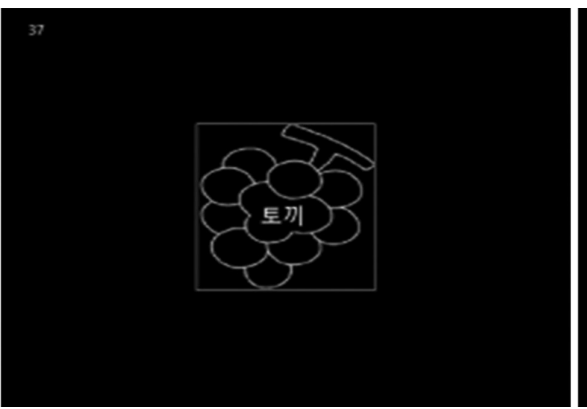

범주 불일치 조건

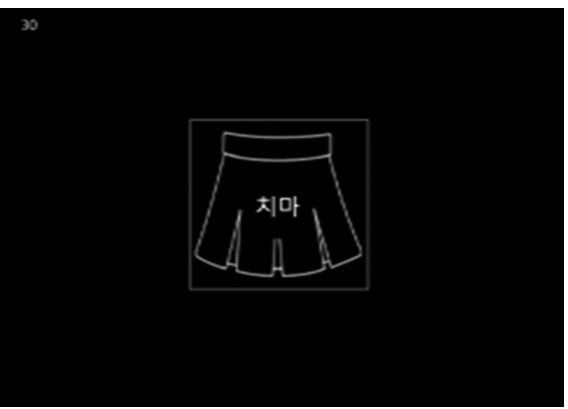

Filler 문항 


\section{국문초록}

\section{그림이름대기에서 나타난 청년층과 노년층의 의미간섭효과}

김오현 $\cdot$ 최소영 $\cdot$ 황민아 ${ }^{3}$

1단국대학교 일반대학원 언어병리학과, ${ }^{2}$ 단국대학교 특수교육대학원, ${ }^{3}$ 단국대학교 특수교육과

배경 및 목적: 본 연구는 청년과 노인을 대상으로 그림-단어 간섭과제에서 범주 일치 여부에 따라 의미처리에 차이를 보이는지 알아보 았다. 방법: 실험 과제는 표적자극(그림)과 방해자극(글자)이 같은 범주에 속하는 조건(범주 일치 조건)과 서로 다른 범주에 속하는 조 건(범주 불일치 조건)으로 구성하였으며, 참가자에게 방해자극을 무시하고 표적자극의 이름을 명명하는 그림-단어 간섭과제를 수행하 도록 하였다. 결과: 실험 결과, 범주 일치 여부에 따른 그림-단어 간섭과제의 정반응 점수에서 노인 집단이 청년 집단에 비해 다소 낮은 수행을 보였으며, 노인 집단의 경우 범주 일치 조건에서 낮은 정확도가 관찰되었다. 이 같은 차이는 반응시간 측정치에서 더 두드러져 노 인 집단이 청년 집단에 비해, 범주 일치 조건이 범주 불일치 조건에 비해 처리 속도가 지연된 것으로 나타났다. 특히 집단(청년/노인)과 범주 일치 여부(일치/불일치)의 상호작용 효과가 통계적으로 유의미하여 범주 일치 조건에서 유발되는 간섭효과가 노인 집단에서 상대 적으로 크게 나타남을 확인할 수 있었다. 논의 및 결론: 이 같은 결과는 노인 집단이 청년 집단에 비해 그림-단어 간섭과제에서 목표자 극에 주의를 유지하기 어렵고, 이로 인해 더 낮은 의미처리 수행을 보이게 됨을 시사하였다.

핵심어: 청년, 노인, 그림-단어 간섭과제, 의미처리능력

이 논문은 제 1 저자의 석사학위 논문을 요약한 것임.

\section{참고문헌}

강연욱(2006). K-MMSE (Korean-Mini Mental State Examination)의 노인 규준 연구. 한국심리학회지: 일반, 25, 1-12. 강연욱, 나덕렬, 한승혜(1997). 치매환자들을 대상으로 한 K-MMSE의 타당도연구. 대한신경과학회지, 15, 300-308. 고선희, 최경순, 황민아(2010). 읽기이해부진아동의 다의어 의미 처리 특성. 언어청각장애연구, 15, 348-356.

구민모(2014). 의미간섭효과 : 외래어 연구. 언어과학연구, 68, 1-18.

구민모, 남기춘(2007). 말소리 산출에서 단어빈도효과의 위치: 그림-단어간섭과제에서 나온 증거. 말소리, 62, 51-68.

김정완, 김향희(2009). 노년층 의사소통능력에 대한 문헌연구. 언어청각장애연구, 14, 495-513.

김정완, 황재호, 김수련, 김향희(2013). 정상 노인의 연령에 따른 주의력 및 이름대기 능력의 차이. 언어치료연구, 22, 25-44.

김한샘(2005). 현대 국어 사용 빈도 조사2. 서울: 국립국어원.

김향희(2012). 신경언어장애. 서울: 시그마프레스.

박순혁(2015). 인지노화와 언어: 심리언어학 접근 현대문법연구, 83, 25-39.

박지윤, 이고은, 이혜원(2013). 한국어 음운정보 산출에서 노화의 영향: 청년과 노인의 설단현상. 인지과학, 24, 111-132.

손영숙, 양혜진(2006). 선택적 주의가 반구간과 반구내의 반응간섭에 미치는 영향 한국심리학회지: 실험, 18, 263-280.

안석환, 이윤정, 이도준(2015). 중복간섭: 단어-사진 스트룹 과제를 통한 공동 활성화 모형검증. 한국심리학회지:인지 및 생물, 27, 313-319.

양윤희, 임동선, 배경란(2015). 학령기 단순언어장애 아동의 어휘학습 예측요인: 의미점화 및 간섭효과. 언어청각장애연구, 20, 1-12.

이지영, 민수정, 이도준(2011). 스트룹 간섭의 희석 및 중복효과. 인지과학, 22, 469-494.

임지향, 이도준(2010). 지각적 부담과 범주 별 희석이 시각 탐색에 미치는 영향. 인지과학, 21, 177-197.

David W. Carroll (2007). 언어심리학(이광오, 박현수 역). 서울: 박학사.

Paul Whitney (2003). 언어심리학(이승복, 한기선 역). 서울: 시그마프레스. 